\title{
Herpes zoster ophthalmicus reduction: implementation of shingles vaccination in the UK
}

Eye (2014) 28, 247-248; doi:10.1038/eye.2013.303

From 1 September 2013, national herpes zoster (HZ) or shingles immunisation was introduced in the UK. ${ }^{1,2}$ It will be routinely offered to 70-year-olds, as a single subcutaneous dose. ${ }^{3}$ Only those who are moderately and severely immunosuppressed are contraindicated for this live attenuated vaccine. ${ }^{3}$ It can be coadministered with (seasonal) inactivated influenza vaccine and pneumococcal polysaccharide vaccine. A catch-up campaign also began, targeting specifically 79-year-olds in the current year. ${ }^{1,2}$ Zostavax (manufactured by Sanofi Pasteur, Lyon, France) is the only marketauthorised vaccine available in the UK. ${ }^{4}$

Shingles is caused by reactivation of latent varicella zoster (VZ) virus. Most people in the UK are infected with VZ in childhood, resulting in chickenpox, an unpleasant but generally mild disease. Following chickenpox infection, virus enters the sensory nerves and travels to the sensory dorsal root ganglia, establishing a permanent latent infection. Reactivation causes shingles and can occur many years later, with an estimated lifetime risk of $25 \% .{ }^{5}$ Reactivation is most commonly associated with immune senescence in aging, although can also occur in association with other immunosuppressive conditions such as taking immunosuppressive therapy and HIV.

Shingles usually begins with unusual skin sensations and pain in the affected area. Sufferers may experience headache, malaise, and fever. ${ }^{3}$ For herpes zoster ophthalmicus (HZO) patients, there can be a pain while brushing the hair. Within days, a unilateral vesicular rash appears across the affected area;
A Potts ${ }^{1}$, GJ Williams 2 , JA Olson ${ }^{3}$, KGJ Pollock 1 , $\mathrm{H}_{\text {Murdoch }}{ }^{1}$ and JC Cameron ${ }^{1}$

in strongly immunosuppressed individuals, different dermatomes may be affected concurrently. The affected area is often painful, may be associated with paraesthesia and can be intensely itchy. Side effects of shingles such as rash and pain are thought to be attenuated by rapid antiviral therapy (within $72 \mathrm{~h}$ ). Pain that persists for or appears longer than 3 months after rash is termed postherpetic neuralgia (PHN).

$\mathrm{HZO}$ is defined by shingles involvement in the ophthalmic division of the trigeminal nerve. This includes a surface region of the scalp, forehead, and the eye, from the vertex down to the infraorbital area, including tip of the nose, sinus, tear duct, and the eye lid. Internally, this involves the nerves associated with the scalp, forehead and the eye, including the optic nerve. $\mathrm{HZO}$ incidence estimates range from $10-20 \%{ }^{6}$ to $2.5 \%{ }^{7}$ of all $\mathrm{HZ}$ cases. Incidence has been up to $50 \%$ in the past, in those who did not receive antiviral therapy. ${ }^{8} \mathrm{HZO}$ cases typically present with rash localised to within the hairline, or more dramatically affecting the forehead and nose. ${ }^{6}$ 'Hutchison's sign' (an indicator of eye involvement if a rash is present on the tip, side, or root of the nose) was previously thought to be a strong predictor of ophthalmic

involvement, ${ }^{8}$ but this is now thought to be less useful. ${ }^{9}$ Estimates suggest that among patients with HZO: $34 \%$ suffer mild visual loss; $5 \%$ suffer moderate visual loss; and 5\% suffer severe visual loss. ${ }^{10}$

In unusual cases of $\mathrm{HZO}$, acute occular involvement is apparent at first consultation with a general practitioner. This may be a swollen or ptotic eyelid, conjunctivitis, or keratitis that may reduce vision. Most cases of
${ }^{1}$ Vaccine Preventable Diseases, Health Protection Scotland, NHS National Services Scotland, Meridian Court, Glasgow, UK

${ }^{2}$ Tennant Institute of Ophthalmology, Gartnavel General Hospital, Glasgow, UK

${ }^{3}$ The Eye Clinic, Aberdeen Royal Infirmary, Aberdeen, UK

Correspondence: A Potts, Vaccine Preventable Diseases, Health Protection Scotland, NHS National Services Scotland, Meridian Court, 5 Cadogan Street, Glasgow, UK. Tel: +44 (0)141 282 2931; Fax: +44 (0)141300 1172 . E-mail: alison.potts@ nhs.net 
eye involvement develop within 3-4 weeks of initial primary care diagnosis ${ }^{11}$ and completion of an initial course of antiviral therapy. Following an initial acute phase, HZO may become chronic or relapsing in nature, and may require years of treatment.

All ophthalmic tissues may be involved, but of those affected, the majority of acute lesions involve the eyelids and lacrimal ducts, and tend to be transient and resolve quickly. ${ }^{11}$ Keratoconjunctivitis is also common and generally resolves rapidly. ${ }^{11}$ Anterior uveitis can usually be treated with topical steroids; however, there is a tendency to relapse when steroid treatment is tapered. The uveitis can become chronic or take on a relapsing nature over many years, with tissue damage, scarring and necrosis, and potential visual impairment. Retinal involvement is rare but carries a risk of significant visual morbidity, requiring treatment with either oral valaciclovir or intravenous acyclovir and oral prednisolone therapy. Optic nerve involvement, ocular motor palsies ${ }^{12}$ and encephalitis ${ }^{13}$ are all rare but significant complications of $\mathrm{HZO}$.

Clinical trials with the $\mathrm{HZ}$ vaccine have indicated that it is well-tolerated, safe, and effective. ${ }^{14,15}$ In a selected healthy population of $60+$-year-olds who had a previous history of chickenpox, the vaccine was shown to reduce shingles incidence by $51 \%$ and PHN by $66 \% .{ }^{14}$ In an unselected $65+$-year-old population of those registered with Medicare in the USA, these end points were shown to be slightly lower (48\% reduction in HZ incidence; $59 \%$ reduction in $\mathrm{PHN}){ }^{15}$

In the UK, immunisation policy is advised by the Joint Committee on Vaccination and Immunisation. ${ }^{16}$

The decision to advise the introduction of $\mathrm{HZ}$ vaccine ${ }^{17}$ was informed by the UK modelling work that estimated cost-effectiveness on the basis of vaccine trial data and UK data on primary care HZ consultations, hospitalisations, deaths, associated pain, and PHN. ${ }^{18}$ Identification and treatment of HZO was included in this analysis but was not identified separately, partly due to lack of specific data. This modelling work informed the recommended ages for immunisation.

In Scotland, we estimate that around 7000 cases of HZ are diagnosed in primary care every year in those over 70 years, with up to 600 hospitalisations. ${ }^{2}$ Data from one large emergency eye clinic in Scotland agree with previous estimates of around $2.5 \% \mathrm{HZ}$ cases having ocular involvement. ${ }^{7}$ Health Protection Scotland, the national organisation in Scotland with responsibility for public health and national surveillance, ${ }^{19}$ will work with clinical ophthalmologists to estimate the burden of HZO on the population of Scotland and to identify vaccineeffectiveness in reducing severe illness and sight impairment. Work is ongoing to develop surveillance strategies that will demonstrate long-term benefits in this vulnerable population both for $\mathrm{HZO}$ and for PHN.

\section{References}

1 CMO Letter England, Wales, NI, available at https:/ / www.gov.uk/government/uploads/system/uploads/ attachment_data/file/212235/Shingles_vaccine_letter.pdf.

2 CMO Letter Scotland CMO2013(15) available at http:/ / www.sehd.scot.nhs.uk/cmo/CMO(2013)15.pdf.

3 Green Book-Herpes Zoster chapter, available at https:// www.gov.uk/government/collections/immunisationagainst-infectious-disease-the-green-book.

4 Electronic Medicines Compendium website, summary of product characteristics for Zostavax http:// www.medicines.org.uk/emc/medicine/25927.

5 Miller E, Marshall R, Vurdien J. Epidemiology, outcome and control of varicella-zoster infection. Rev Med Microbiol 1993; 4: 222-230.

6 Ragozzino MW, Melton 3rd LJ, Kurland LT, Chu CP, Perry HO et al. Population-based study of herpes zoster and its sequelae. Medicine (Baltimore) 1982; 61: 310-316.

7 Yawn BP, Wollan St PC, Sauver JL, Butterfield LC. Herpes zoster eye complications: rates and trends. Mayo Clin Proc 2013; 88: 562-570.

8 Liesegang TJ. Herpes zoster ophthalmicus-natural history, risk factors, clinical presentation and morbidity. Ophthalmology 2008; 115: S3-S12.

9 Zaal MJ, Völker-Dieben HJ, D’ Amaro J. Prognostic value of Hutchinson's sign in acute herpes zoster ophthalmicus. Graefes Arch Clin Exp Ophthalmol 2003; 241: 187-191.

10 Nithyanandam S, Stephen J, Joseph M, Dabir S. Factors affecting visual outcome in herpes zoster ophthalmicus: a prospective study. Clin Experiment Ophthalmol 2010; 38: 845-850.

11 Marsh RJ, Cooper M. Ophthalmic herpes zoster. Eye 1993; 7: 350-370.

12 Chhabra MS, Golnik KC 2013; Recovery of ocular motor cranial nerve palsy after herpes zoster ophthalmicus. J Neuroophthalmol epub ahead of print 18 September 2013.

13 Haargaard B, Lund-Andersen H, Milea D. Central nervous system involvement after herpes zoster ophthalmicus. Acta Ophthalmologica 2008; 86: 806-809.

14 Oxman MN, Levin MJ, Johnson GR, Schmader KE, Straus SE, Gelb LD et al. A vaccine to prevent herpes zoster and postherpetic neuralgia in older adults. N Engl J Med 2005; 352: $2271-2284$.

15 Langan SM, Smeeth L, Margolis DJ, Thomas SL. Herpes zoster vaccine effectiveness against incident herpes zoster and post-herpetic neuralgia in an older US population: a cohort study. PLoS Med 2013; 10: e1001420.

16 JCVI webpage https://www.gov.uk/government/ policy-advisory-groups/joint-committee-on-vaccinationand-immunisation.

17 JCVI statement on HZ vaccine, issued 29 March 2010, available at: http://webarchive.nationalarchives.gov.uk/ 20120907090205/http://www.dh.gov.uk/ab/JCVI/ DH_094744.

18 van Hoek AJ, Gay N, Melegaro A, Opstelten W, Edmunds WJ. Estimating the cost-effectiveness of vaccination against herpes zoster in England and Wales. Vaccine 2009; 27: 1454-1467.

19 HPS website http://www.hps.scot.nhs.uk/. 